\title{
Prescribing opioids and psychotropic drugs in pregnancy
}

\author{
(0) $\Theta \Theta$ OPEN ACCESS \\ Increases in prescribing are a major concern
}

\begin{abstract}
Stephen W Patrick assistant professor of pediatrics and health policy, neonatologist ${ }^{12}{ }^{3}$, William 0 Cooper Cornelius Vanderbilt professor of pediatrics and health policy ${ }^{12}$, Matthew M Davis professor of pediatrics, medicine, medical social sciences, and preventive medicine ${ }^{45}$
\end{abstract}

\footnotetext{
${ }^{1}$ Vanderbilt University, Nashville, TN, USA; ${ }^{2}$ Vanderbilt Center for Health Services Research, Nashville, TN, USA; ${ }^{3}$ Vanderbilt Center for Addiction Research, Nashville, TN, USA; ${ }^{4}$ Ann \& Robert H. Lurie Children's Hospital of Chicago, Chicago, IL, USA; ${ }^{5}$ Northwestern University Feinberg School of Medicine, Chicago, IL, USA
}

Over the past two decades, increasing use of opioid pain relievers has led to myriad complications in communities throughout the US. In 2015, every 15 minutes one American died from an opioid related overdose-which is more frequent than deaths from vehicle crashes. ${ }^{1}$ Given the rapid rise and scope of the US opioid epidemic, it should not be a surprise that nearly every segment of society has been affected, including pregnant women and their infants. Infants exposed to opioids are at risk of neonatal opioid withdrawal syndrome, also known as neonatal abstinence syndrome (NAS), which is commonly characterized by difficulty feeding, respiratory problems, irritability, hypertonia, insomnia, and seizures, leading to more complicated and costly admissions to hospital. ${ }^{2}$ In the US, rates of neonatal abstinence syndrome grew fivefold over the past decade, reaching a rate of one affected infant born every 25 minutes. Importantly, not all infants exposed to opioids develop withdrawal, for reasons that remain unclear. In a linked paper, Huybrechts and colleagues (doi:10.1136/bmj.j3326) find a possible reason for differences in risk-concurrent prescription of psychotropic medications. ${ }^{4}$ The authors used a US cohort of 200000 pregnant women enrolled in the Medicaid program-a government sponsored program that pays for healthcare services-all of whom filled a prescription for an opioid. They examined whether the risk of neonatal abstinence syndrome was increased among infants whose mothers were co-prescribed a psychotropic medication. They found that use of antidepressants (relative risk 1.34, 95\% confidence interval 1.22 to 1.47$)$, benzodiazepines $(1.49,1.35$ to 1.63$)$, and gabapentin (1.61, 1.26 to 2.06) increased the risk. They also found that exposure to two or more of these medications more than doubled the odds $(2.05,1.77$ to 2.37$)$ compared with odds in pregnant women prescribed opioids alone.
These data were derived from hospital administrative records, which can be prone to misclassification bias and cannot account for illicit co-exposures (such as cocaine); nevertheless, the data are unique providing the power to detect rare outcomes, and these findings are important in targeting prevention efforts and potentially in tailoring treatment of opioid exposed infants. Huybrechts and colleagues' study highlights how the opioid epidemic affects women and infants in the US, where rates of prescribing are nearly four times higher than in Europe. ${ }^{5}$ While prescriptions for opioids have declined slightly in the US since $2012,{ }^{5}$ studies of the pregnant women enrolled in Medicaid found that, depending on the state, $9.5 \%$ to $41.6 \%$ were prescribed at least one opioid in pregnancy ${ }^{67}$ In addition, the growth of use of prescribed opioids has been temporally associated with an increase in opioid use disorder among pregnant women in the US, ${ }^{2}$ particularly in rural areas. ${ }^{8}$

Policy approaches to the opioid epidemic must acknowledge that untreated opioid use disorder, anxiety, and depression are harmful for both mother and infant; put simply, healthier mothers have healthier babies. The large expansion of opioid prescribing and prescribing of psychotropic medications to pregnant women, however, raise major concerns. Most of all medications in use today lack enough information to determine their safety in pregnancy. ${ }^{9}$ For instance, gabapentin is categorized as a pregnancy category $\mathrm{C}$ medication, with evidence of fetal harm in animal experiments but inadequate controlled studies in humans. ${ }^{10}$

\section{Treating for two}

Use of medications in pregnancy must balance the health of the mother with the potential impact on developing fetus. These concerns led the US Centers for Disease Control and Prevention to launch an initiative called "Treating for Two," emphasizing 
the value of better research and reliable guidance that will better inform women's and clinicians' decisions about medication use during pregnancy (www.cdc.gov/pregnancy/meds/ treatingfortwo/index.html).

For clinicians who provide care for pregnant women and their children, these data have some additional important implications. Given clinical challenges in predicting risk of withdrawal among infants exposed to opioids, the American Academy of Pediatrics suggests that all such infants should be observed for four to seven days after birth to monitor for signs of withdrawal. ${ }^{11}$ Huybrechts and colleagues found substantial differences in risk of withdrawal based on exposure to specific psychotropic agents, suggesting opportunities to tailor postnatal monitoring and treatment for the highest risk infants. ${ }^{4}$

Lastly, these findings suggest a clear need for a comprehensive, evidence informed strategy regarding opioid use in pregnancy. To be effective, the strategy would specify opportunities for intervention in clinical and public health settings in all time periods related to pre-pregnancy, antepartum/prenatal, peripartum/perinatal, and postpartum/infancy. There remains a paucity of clinical guidance for obstetricians and pediatricians caring for the mother-child unit; development of a strategy will help to prioritize the development of specific evidence. ${ }^{12}$ As the US opioid epidemic accelerates in complexity, there is an urgent need to focus resources on this issue, including expansion of research funding for drug safety in pregnancy and improvement of outcomes for mothers and infants affected by opioid use disorder, more funding for the prevention of the disorder, and an expansion of treatment options for affected mothers and their infants.

Competing interests: We have read and understood the BMJ Group policy on declaration of interests and have no interests to declare.

Provenance and peer review: Commissioned, not peer reviewed
1 Rudd RA, Seth P, David F, Scholl L. Increases in Drug and Opioid-Involved Overdose Deaths - United States, 2010-2015. MMWR Morb Mortal Wkly Rep 2016;358:1445-52. doi:10.15585/mmwr.mm655051e1 pmid:28033313.

2 Patrick SW, Schumacher RE, Benneyworth BD, Krans EE, McAllister JM, Davis MM Neonatal abstinence syndrome and associated health care expenditures: United States, 2000-2009. JAMA 2012;358:1934-40. doi:10.1001/jama.2012.3951 pmid:22546608.

3 Patrick SW, Davis MM, Lehmann CU, Cooper WO. Increasing incidence and geographic distribution of neonatal abstinence syndrome: United States 2009 to 2012. J Perinatol 2015;358:650-5. doi:10.1038/jp.2015.36 pmid:25927272.

4 Huybrechts K, Bateman BT, Desai R, et al. Risk of neonatal drug withdrawal after intrauterine co-exposure to opioids and psychotropic medications: cohort study. BMJ 2017;358:j3326.

5 Guy GP Jr, , Zhang K, Bohm MK, et al. Vital Signs: Changes in Opioid Prescribing in the United States, 2006-2015. MMWR Morb Mortal Wkly Rep 2017;358:697-704. doi:10. 15585/mmwr.mm6626a4 pmid:28683056.

6 Desai RJ, Hernandez-Diaz S, Bateman BT, Huybrechts KF. Increase in prescription opioid use during pregnancy among Medicaid-enrolled women. Obstet Gynecol 2014;358:997-1002. doi:10.1097/AOG.0000000000000208 pmid:24785852.

7 Patrick SW, Dudley J, Martin PR, et al. Prescription opioid epidemic and infant outcomes. Pediatrics 2015;358:842-50. doi:10.1542/peds.2014-3299 pmid:25869370.

8 Villapiano NL, Winkelman TN, Kozhimannil KB, Davis MM, Patrick SW. Rural and Urban Differences in Neonatal Abstinence Syndrome and Maternal Opioid Use, 2004 to 2013. JAMA Pediatr 2017;358:194-6. doi:10.1001/jamapediatrics.2016.3750 pmid:27942711.

9 Adam MP, Polifka JE, Friedman JM. Evolving knowledge of the teratogenicity of medications in human pregnancy. Am J Med Genet C Semin Med Genet 2011;358:175-82. doi:10.1002/ajmg.c.30313 pmid:21766440.

10 NEURONTIN (gabapentin): highlights of prescribing information. Pfizer, 2015. https:// www.pfizermedicalinformation.com/en-us/neurontin.

11 Hudak ML, Tan RC. COMMITTEE ON DRUGS COMMITTEE ON FETUS AND NEWBORN American Academy of Pediatrics. Neonatal drug withdrawal. Pediatrics 2012;358:e540-60. doi:10.1542/peds.2011-3212 pmid:22291123.

12 Reddy UM, Davis JM, Ren Z, Greene MF. Opioid Use in Pregnancy, Neonatal Abstinence Syndrome, and Childhood Outcomes: Executive Summary of a Joint Workshop by the Eunice Kennedy Shriver National Institute of Child Health and Human Development, American Congress of Obstetricians and Gynecologists, American Academy of Pediatrics, Society for Maternal-Fetal Medicine, Centers for Disease Control and Prevention, and the March of Dimes Foundation. Obstetrics \& Gynecology. 2017.

Published by the BMJ Publishing Group Limited. For permission to use (where not already granted under a licence) please go to http://group.bmj.com/group/rights-licensing/ permissions

This is an Open Access article distributed in accordance with the Creative Commons Attribution Non Commercial (CC BY-NC 4.0) license, which permits others to distribute, remix, adapt, build upon this work non-commercially, and license their derivative works on different terms, provided the original work is properly cited and the use is non-commercial. See: http://creativecommons.org/licenses/by-nc/4.0/. 